\title{
Analysis of the Discrepancies Between the Vertical Reference Frames of Argentina and Brazil
}

\author{
M.E. Gomez, R.A.D. Pereira, V.G. Ferreira, D. Del Cogliano, R.T. Luz, \\ S.R.C. de Freitas, C. Farias, R. Perdomo, C. Tocho, E. Lauria, and S. Cimbaro
}

\begin{abstract}
The vertical reference frames for Argentina and Brazil present discrepancies due to their different datums and realizations. Thus, since 2008, we have started a series of activities with the aim of unifying the Argentine and Brazilian national vertical networks (NVNs). To achieve this goal, we have connected the two NVNs at three border points by using the geodetic levelling approach. Additionally, the gravity field approach was also applied, based on a suitable representation of the geoid by considering the Earth Gravitational Model (EGM2008) in its full resolution. In this regard, 1266 co-located Global Positioning System (GPS) and levelling benchmarks regularly distributed over Argentina (612) and Brazil (654) were considered. The geodetic levelling approach shows an offset value of $54 \mathrm{~cm}$, which implies that the Argentine vertical reference frame is above that of the Brazilian vertical reference frame. However, the result of the gravimetric approach shows an offset of $57 \mathrm{~cm}$, which implies a difference of approximately $3 \mathrm{~cm}$ between both methods. Hence, since Brazil and Argentina represent a significant part of South America, the solution to the datum problem between both countries could point towards a common vertical reference frame for the Atlantic side.
\end{abstract}

\section{Keywords}

Argentine and Brazilian levelling networks • Geodetic levelling approach • Gravity field approach • Vertical datum connection

M.E. Gomez $(\varangle) \bullet$ D. Del Cogliano • C. Farias • R. Perdomo • C. Tocho

Facultad de Ciencias Astronómicas y Geofísicas, Universidad Nacional de La Plata, La Plata, Argentina

e-mail: megomez@fcaglp.unlp.edu.ar

R.A.D. Pereira

Federal University of Pelotas, Pelotas, Brazil

V.G. Ferreira

School of Earth Sciences and Engineering, Hohai University, Nanjing, China

R.T. Luz

Brazilian Institute of Geography and Statistics, Rio de Janeiro, Brazil

S.R.C. de Freitas

Department of Geomatics, Federal University of Paraná, Curitiba, Brazil

\section{Introduction}

\subsection{Background}

There is an agreement among South American countries to monitor and integrate the National Vertical Networks (NVNs) according to the Geocentric Reference System for the Americas' (SIRGAS) statements (Fortes 1998). A unified vertical datum in South America is important for monitoring common problems related to the environment, engineering, natural resources, land management and cadastral surveying (Ferreira and de Freitas 2011). As part of a bilateral research

E. Lauria $\bullet$ S. Cimbaro

Instituto Geográfico Nacional, Buenos Aires, Argentina 


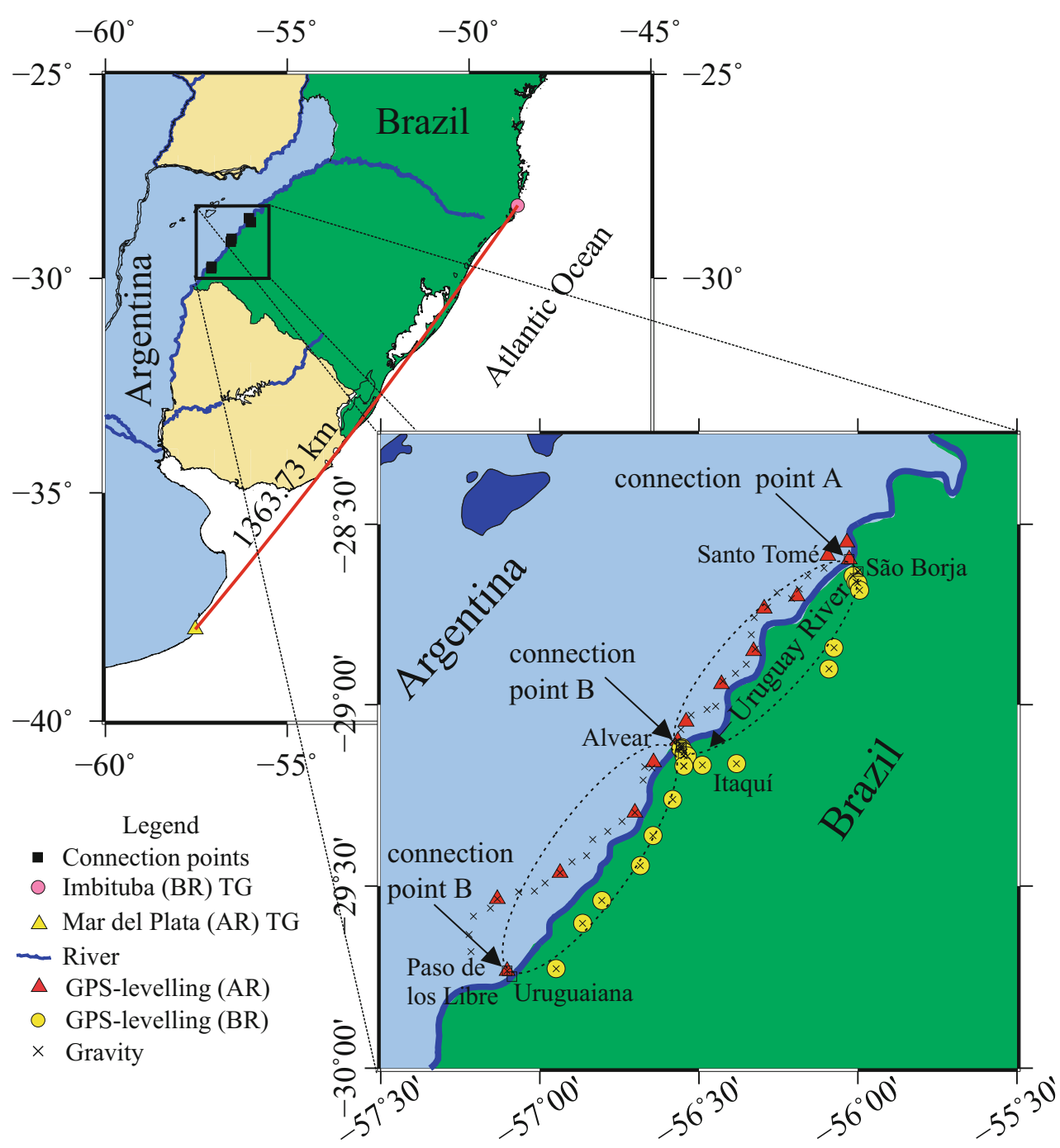

Fig. 1 The study region located in North-east Argentina and Southern Brazil. The enclosed rectangle shows the study area with the three connection points $(\mathrm{A}, \mathrm{B}, \mathrm{C})$ between the two National vertical networks.

project between Argentina and Brazil, the Federal University of Parana (UFPR), Brazil and the National University of La Plata (UNLP), Argentina have started a series of activities that aim to connect the Argentine and Brazilian vertical reference frames. The main purpose of this paper is to present the actions to assess the vertical offset between the Argentine and Brazilian NVNs at three points along the border between both countries (Fig. 1).

One of the early studies relating to the connection between the vertical datums by Heck and Rummel (1990) suggested three approaches to connecting independent vertical reference frames: the oceanographic levelling approach, the geodetic levelling approach, and the gravity field approach. As a first attempt to connect the Argentine and Brazilian NVNs, we considered in this study only the geodetic levelling and the gravity field approaches. We carried out precise geodetic levelling as well as Global Positioning System
Additionally, it shows the distance between the two tide gauges (TG) at Mar del Plata (Argentina) and Imbituba (Brazil) and the location of the levelling circuits (dashed lines) and the GPS-levelling stations

(GPS) surveying on available benchmarks (BMs) in the study region. Additionally, we considered the geoid model derived from Earth Gravitational Model 2008's (EGM2008) spherical harmonic coefficients (Pavlis et al. 2012) and the GPSlevelling dataset for both countries. The particular choice of the EGM2008 was mainly due to its high resolution (5 arcmin). Hence, we were able to determine the offsets by two independent methods, namely, the geodetic levelling and gravity field approaches.

\subsection{Argentine and Brazilian National Vertical Networks}

Levelling activities in Argentina started in 1899, initially using Riachuelo tide gauge (TG) at the Río de la Plata estuary as reference. In 1923, the mean sea level at Mar del Plata TG 
was adopted as the datum of the Argentine height system. In 2012 a readjustment using levelling differences and observed gravity values of the Argentine NVN was carried out by the Instituto Geográfico Nacional (National Geographic Institute of Argentina; IGN) to determine geopotential numbers (Cimbaro et al. 2013, "personal communication"). However, this adjustment was not ready at the time of the realization of the present work.

The Brazilian height network was started as an effort by the Instituto Brasileiro de Geografia e Estatística (Brazilian Institute of Geography and Statistics; IBGE) in 1945. Two different vertical datums were established resulting in two separate networks: Santana to the north of the Amazon River estuary and Imbituba spreading for almost the whole country (Montecino and de Freitas 2014). The origin at Imbituba TG (Fig. 1) was defined in 1957 after nine years of sea-level observations with the mean value centred in 1953. The NVN related to it was subject to eight sequential adjustments in order to include new levelling lines. However, only three global adjustments were performed in 1959, 1993 and 2011. The heights derived from the 1993 and 2011 adjustment realizations were considered in this work.

It is important to mention that both NVNs were realized using the normal-orthometric height system; that is, only reductions based on the normal gravity field were used before the adjustment of the levelling networks. The normalorthometric heights are not able to support height determination with the full physical meaning derived from the ellipsoidal heights obtained by the GPS (Ihde and Sánchez 2005). Despite this, we considered the normal-orthometric heights as an approximation to orthometric heights. Further discussion about the differences between normal-orthometric, normal and orthometric height systems is provided in Filmer et al. (2010). Since the tidal corrections were not applied to the levelling observations in Argentina and Brazil, the normal-orthometric heights were considered to refer to the mean tide system in this particular study.

\section{$2 \quad$ Methodology and Dataset}

\subsection{Levelling}

We considered four levelling lines along Uruguay River (Fig. 1). Doing so, we connected the Argentine (along the west bank of the river) with the Brazilian (east bank) levelling lines at three border points. In this regard, two circuits (northern and southern circuits) of about $150 \mathrm{~km}$ length were formed. We established six BMs that materialize the connection points (CPs) along the international border of Argentina and Brazil. They are Santo Tomé/São Borja (CP A), Alvear/Itaquí (CP B) and Paso de los Libres/Uruguaiana (CP C) (Fig. 1). The distances between CPs are $4.6 \mathrm{~km}$,
$0.6 \mathrm{~km}$ and $2.3 \mathrm{~km}$, respectively. Due to the distance and characteristics of the study region, the levelling surveys were conducted by using spirit levelling and trigonometric levelling. The accuracy of these observations is in agreement with the levelling specifications of $4 \mathrm{~mm} \sqrt{k}$, where $k$ is the length of the levelled line in $\mathrm{km}$.

\subsection{Earth Gravitational Model 2008 (EGM2008)}

The geopotential model EGM2008 (Pavlis et al. 2012) was included in the present work in order to analyse the offset and to connect both NVNs. EGM2008 is given as series of spherical harmonic coefficients up to degree and order $(\mathrm{d} / \mathrm{o})$ 2159 with additional coefficients up to d/o 2190. According to Yi and Rummel (2014), EGM2008 is the most comprehensive representation and the highest resolution of the Earth's gravitational field currently available. The particular choice of EGM2008 was mainly due to its high resolution.

\subsection{GPS-Levelling Dataset}

GPS observations were carried out at 14 BMs over the Argentine side and 22 over the Brazilian side to obtain "geoid heights" (the quotation marks here are because we considered the normal-orthometric heights to be an approximation of the orthometric heights). The ellipsoidal coordinates $(\varphi, \lambda, h)$ refer to the SIRGAS reference frame SIR10P01, through MECO GPS station, located in Argentina. The measurements were performed by means of Leica and Trimble double frequency receivers. Static mode was applied and each session lasted from three to six hours. This GPSlevelling dataset was used to check the stability of the benchmarks in the study region. Additionally, another set of GPSlevelling data was used; there were 612 points over Argentina and 654 over Brazil (related to the 2011 realization), after the removal of outliers.

The information about the uncertainties of GPS-derived ellipsoidal heights and the normal-orthometric heights were not considered here. Additionally, the ellipsoidal heights are in a tide-free system (Poutanen et al. 1996), while the normal-orthometric heights are in a mean-tide system. To guarantee the consistency of the comparisons, we reduced the orthometric heights to a tide-free system (Ekman 1989). Although the International Association of Geodesy's (IAG) resolution No. 16 of 1983 recommends the zero-tide convention, we adopted the tide-free system in our comparisons due to its widespread use among the GPS community; the comparisons are not influenced by this particular choice due to differencing. 


\subsection{Treatment of Systematic Data Errors}

The difference between the geoid heights from GPS-levelling $\left(N_{G P S}\right)$ and those computed by using EGM2008 $\left(N_{E G M}\right)$ is given as:

$$
\Delta N_{i}=N_{G P S_{i}}-N_{E G M_{i}},
$$

where the subscript index $i$ indicates the considered point. $N_{G P S}$ represents the height of the national height reference frame above a reference ellipsoid, here the Geodetic Reference System 1980 (GRS80). However, following Rülke et al. (2012) and Kotsakis et al. (2012) significant systematic effects may remain in the pure offset estimation if Eq. (1) is considered. To remove the systematic effects in height simultaneously with the estimation of the offsets $(\delta H)$, the observation Eq. (1) for $\Delta N_{i}$ can be written as (Kotsakis et al. 2012):

$$
\Delta N_{i}=\delta H_{i}+x_{1}\left(\varphi_{i}-\varphi_{0}\right)+x_{2}\left(\lambda_{i}-\lambda_{0}\right) \cos \varphi_{i}+v_{i},
$$

where the unknowns $\delta H_{i}, x_{1}$ and $x_{2}$ represent the offset $(\mathrm{cm})$, a north-south and west-east tilt $(\mathrm{cm} /$ degree) related to the centroid of the network $\left(\varphi_{0}, \lambda_{0}\right)$, respectively, and the term $v_{i}$ represents the random residual.

\section{$3 \quad$ Results}

The results and analysis of the determined offsets were derived in two ways: first, the closures of the circuits by considering the geodetic levelling approach and, second, the comparison of GPS-levelling against a global geoid model (EGM2008) by considering the gravity field approach.

\subsection{The Geodetic Levelling Approach}

The evaluation of closures of the two circuits presented at Fig. 1 indicates $-0.0001 \mathrm{~m}$ in the southern loop and $0.0995 \mathrm{~m}$ in the northern one. The almost $10 \mathrm{~cm}$ misclosure obtained for the northern circuit is an unexpected result and suggests an inconsistency within it. It is important to mention that this misclosure error of $10 \mathrm{~cm}$ is related to heights estimated in the 1993 adjustment of the Brazilian NVN. Surprisingly, if the heights associated with the current realization of the Brazilian height system are considered (i.e. the 2011 adjustment) the misclosure error reaches the magnitude of $40 \mathrm{~cm}$ in the northern circuit. This indicates a single error in a particular BM that could not be identified because this study did not include all the points used in the 2011 adjustment. Indeed, this is not the first time that such problem has been identified with the Brazilian levelling lines. Hernández et al. (2002) reported a height difference between Brazilian and Venezuelan levelling networks of $3.45 \mathrm{~m}$.
Table 1 Level offset between the Argentine and Brazilian NVNs at the connection points A, B and C (Fig. 1)

\begin{tabular}{lll}
\hline & \multicolumn{2}{l}{$\delta H_{(A R)(B R)}(\mathrm{m})$} \\
\cline { 2 - 3 } Connection points & 1993 & 2011 \\
\hline Santo Tomé/São Borja (A) & -0.8195 & -0.9802 \\
\hline Alvear/Itaquí (B) & -0.7008 & -0.5457 \\
\hline Passo de los Libres/Uruguaiana (C) & -0.7210 & -0.5280 \\
\hline
\end{tabular}

The negative values indicate that the Brazilian vertical reference frame is below the Argentine vertical reference frame

The observed offset between the Argentine and Brazilian levelling networks at the CPs (Fig. 1) are shown in Table 1. The magnitude of the observed values is rather inhomogeneous, especially at CP A (São Borja/Santo Tomé) and even worst when considering the Brazilian heights related to the 2011 realization. This value reaches $\sim 82 \mathrm{~cm}$ while B (Itaquí/Alvear) and C (Uruguaiana/Paso de Los Libres) $\sim 71 \mathrm{~cm}$ and $\sim 72 \mathrm{~cm}$, respectively considering the Brazilian heights related to 1993 realization. As we also can see from Table 1, the situation is even worse when conserving the 2011 realization.

\subsection{Gravity Field Approach}

In this particular comparison, the errors of the ellipsoidal heights, orthometric heights and geoid heights from EGM2008 were neglected. The statistics of the evaluation in terms of minimum, maximum, mean, standard deviation (SD) and root mean square error (RMSE) are summarized in Fig. 2 for both NVNs. The EGM2008-derived geoid heights fit marginally better with the Argentine GPSlevelling network than with the Brazilian in terms of SD as Fig. 2 shows. It is well known that the gravity anomaly values used for the EGM2008 project were of a proprietary nature or unavailable (e.g. Amazon region) over Brazilian territory (Pavlis et al. 2012). In such cases, the EGM2008 incorporated the gravity data up to a d/o 900 (Pavlis et al. 2013). Beyond d/o 900 "fill-in" gravity anomalies were applied, which implies that over Brazil EGM2008-derived geoid heights would have less accuracy in comparison with Argentina.

We examined the systematic effects and their impact on the estimated discrepancy between the Argentine and Brazilian vertical reference frames. The geoid height differences computed through Eq.(1) are presented in Fig. 2 in order to emphasize the systematic spatial tilt present in the GPSlevelling networks. It is clear that there is a significant eastwest tilt, whereas the north-south tilt appears to be less important over the Argentine NVN. Over the Brazilian NVN the situation seems to be quite a lot better than over the Argentine one. The residuals for both countries are characterized by a strong bias in the Andean region (Argentina) and 


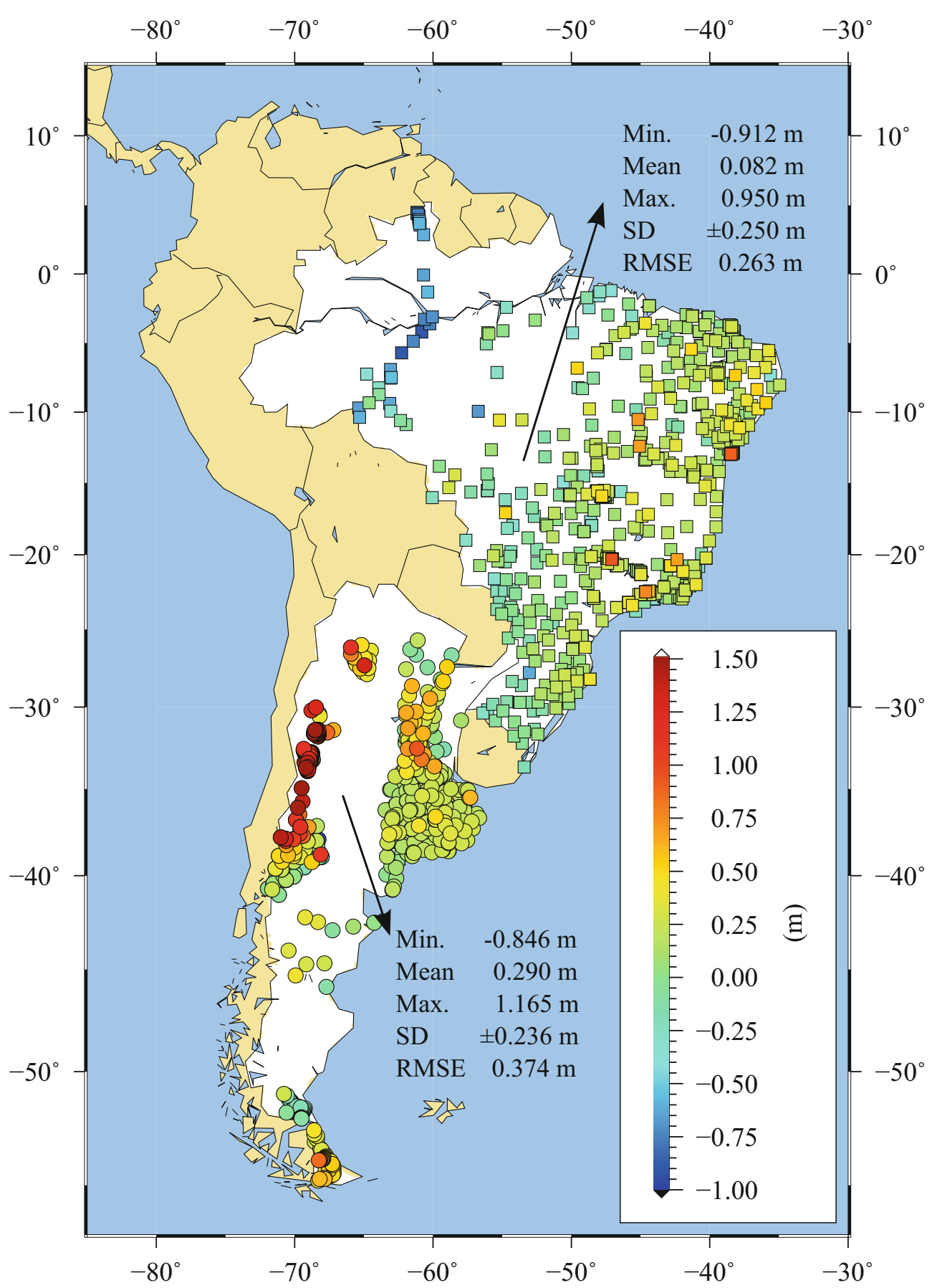

Fig. 2 Statistics and spatial distribution of the differences between GPS-levelling and EGM2008-derived geoid heights 
Table 2 Estimated offsets and parameters for Argentina and Brazilian GPS-levelling corresponding to the bias corrector model in Eq. (2) and their respective RMSEs of the adjusted residuals (goodness of model fit)

\begin{tabular}{|c|c|c|c|c|c|c|c|}
\hline \multirow{2}{*}{ Network } & \multirow{2}{*}{ \# of Points } & \multirow{2}{*}{$\varphi\left(^{\circ}\right)$} & \multirow{2}{*}{$\lambda\left(^{\circ}\right)$} & \multirow{2}{*}{$\delta H(\mathrm{~cm})$} & \multicolumn{2}{|c|}{ Tilt (cm/degree) } & \multirow{2}{*}{ RMSE $(\mathrm{cm})$} \\
\hline & & & & & & & \\
\hline & & & & & $x_{1}$ & $x_{2}$ & \\
\hline Argentine & 612 & -36.202 & -62.272 & $29.4 \pm 0.8$ & $1.5 \pm 0.1$ & $-3.4 \pm 0.4$ & 20.8 \\
\hline Brazilian & 654 & -15.469 & -46.314 & $8.1 \pm 0.8$ & $-0.8 \pm 0.1$ & $2.5 \pm 0.1$ & 19.9 \\
\hline
\end{tabular}

Amazon region (Brazil). Improvement in gravity coverage in those regions will play a central role in reducing the omission error of global geopotential models and in increasing the reliability of local geoid models of high-resolution.

In order to estimate the offsets for each NVN with respect to the EGM2008 geoid level, the apparent systematic bias shown in Fig. 2 was removed using Eq.(2). The resulting offsets $\delta H$ and the parameters $x_{1}$ and $x_{2}$ are presented in Table 2 . The RMSE values were calculated by using the adjusted residuals from the least-squares estimation. Because the GPS-levelling and the EGM2008-derived geoid heights come from independent methods, it is assumed that the RMSE of the residuals shows which network is stronger affected by systematic errors in the levelling.

Considering the GPS-levelling distribution over Argentina, the north-south and the west-east tilts estimated by means of Eq. (2) are $1.5 \mathrm{~cm} /$ degree and $-3.4 \mathrm{~cm} /$ degree, respectively. In the case of Brazil, they are $-0.8 \mathrm{~cm} /$ degree and $2.5 \mathrm{~cm} /$ degree, respectively. Although the tilt estimates of the spirit levelling approach and the gravity field approach refer to different reference surfaces, this provides a quite good agreement between the two surfaces. The east-west tilt of $-3.4 \mathrm{~cm} /$ degree related to the centroid of the GPSlevelling distribution over Argentina is equal to the levelling specification of $4 \mathrm{~mm} \sqrt{k}\left(\sim 3.4 \mathrm{~cm} /\right.$ degree at $\left.\varphi_{0}\right)$. Despite this, the RMSE of the residuals presented in Table 2 shows that both GPS-levelling networks have the same quality.

\section{Discussion}

In order to check the quality of the both approaches adopted here, we compared the levelling results (geodetic levelling approach) with those coming from comparing the GPSlevelling data with the EGM2008 model. According to Fig. 1, the level differences between the two NVN were directly determined at the CPs A, B and C. The value obtained at the CP A (Santo Tomé/São Borja) presents a large discrepancy with respect to the other two CPs $\mathrm{B}$ and $\mathrm{C}$ and deserves further investigation. To explain the large value (of about $10 \mathrm{~cm}$ ) of the misclosure of the northern circuit, the first suspicion is an unidentified error in the levelling height of the point A. This could be supported by the fact that the geoid gradient between this point $\mathrm{A}$ and the previous Brazilian
$\mathrm{BM}$ is $10 \mathrm{~cm} / \mathrm{km}$ and this value is reduced to $0.1 \mathrm{~cm} / \mathrm{km}$ when using geometric levelling and EGM2008-derived geoid heights (excluding the closest Brazilian BM). A second levelling campaign confirmed the physical height adopted for the connection BM. Because of this uncertainty about CP A, we considered only $\mathrm{CPs} B$ and $\mathrm{C}$, which provided a mean value of $0.7109 \mathrm{~m}$ and $0.5368 \mathrm{~m}$ related to the realization of 1993 and 2011, respectively.

The offset value obtained by considering the gravity field approach provided a mean value of approximately $-21.3 \pm$ $1.1 \mathrm{~cm}$ related to the 2011 realization. Unfortunately, we do not have the GPS-levelling data related to the 1993 realization. Sánchez (2007) provided an estimated offset between the Argentine and Brazilian vertical reference frames of approximately $-26 \mathrm{~cm}$ based on EIGEN-CG03C model up to d/o 360 evaluated at each tide gauge collocated with SIRGAS stations, namely, Imbituba $(-20 \mathrm{~cm})$, Brazil and Mar del Plata $(+6 \mathrm{~cm})$, Argentina. In Ihde and Sánchez (2005), it is possible to infer two values of approximately $-35 \mathrm{~cm}$ and $+11 \mathrm{~cm}$ by considering the connection through Uruguay and Paraguay, respectively obtained from spirit levelling.

The mean estimated offset obtained by the gravity field approach is somewhat different to that of the geodetic levelling approach, which provided a mean value of $-53.68 \pm$ $2.3 \mathrm{~cm}$ related to the 2011 realization. It must be remarked that the gravity field approach is realized over a broad area while the levelling approach was conducted in a single small region. To account for this, the estimated offsets, tilts and the coordinates of the centroids $\left(\varphi_{0}, \lambda_{0}\right)$ of Argentina and Brazil (Table 2) were used to calculate $\Delta N_{A R}$ and $\Delta N_{B R}$ for the connection points (cf. Rülke et al. (2012) for details). We found the values of $+18.48 \mathrm{~cm}$ and $-38.98 \mathrm{~cm}$ for $\triangle N_{A R}$ and $\Delta N_{B R}$, respectively, which implies an offset of $-57.46 \mathrm{~cm}$ at the connection points.

\section{Summary and Outlook}

The relative offsets between the Argentine and Brazilian vertical networks have been determined by using geodetic levelling and gravity field approaches. Our findings show that the estimated offset obtained by considering the geodetic levelling approach is approximately $-72 \mathrm{~cm}$ if the Brazilian height system realization of 1993 is used, and $-54 \mathrm{~cm}$ if 
the realization of 2011 (official) is used at two of the three CPs. We excluded CP A (Fig. 1) that indicated an offset of $-82 \mathrm{~cm}$ and $-98 \mathrm{~cm}$ for the 1993 and 2011 realization, respectively. This shows inconsistencies between the two realizations of the Brazilian height system. For the gravity field approach, the offset between both NVNs is $-57 \mathrm{~cm}$, which implies a difference of approximately $3 \mathrm{~cm}$ between the two approaches, that is, between geodetic levelling and gravity field. The negative values indicate that the Brazilian vertical reference frame is below the Argentine vertical reference frame. Since Brazil and Argentina represent a significant part of South America, the solution of the datum problem between both countries could point towards a common vertical reference frame for the Atlantic side. Future work should benefit greatly by using data from the new adjustment of the Argentine NVN, which is based on geopotential numbers. Additionally, investigation of the eventual deformations of the Brazilian 2011 realization should be carried out.

Acknowledgements The authors thank CNPq (Brazilian National Council for Scientific and Technological Development) and CONICET (Argentine National Council for Scientific and Technical Research) for their financial support. We also thank the IBGE and IGN for providing the GPS-levelling data over Brazil and Argentina, respectively. We are grateful to the Associate Editor and the three reviewers for their remarks, which improved the manuscript.

\section{References}

Ekman M (1989) Impacts of geodynamic phenomena on systems for height and gravity. Bull Géod 63(3):281-296. Doi: 10.1007/BF02520477

Ferreira VG, de Freitas SRC (2011) Geopotential numbers from GPS satellite surveying and disturbing potential model: a case study of Parana, Brazil. J Appl Geod 5(3-4):155-162. Doi: 10.1515/JAG.2011.016

Filmer MS, Featherstone WE, Kuhn M (2010) The effect of EGM2008based normal, normal-orthometric and Helmert orthometric height systems on the Australian levelling network. J Geod 84(8):501-513. Doi: 10.1007/s00190-010-0388-0

Fortes LPS (1998) An overview of the SIRGAS project. In: Advances in Positioning and Reference Frames, IAG Symposia, vol 118, pp 167167. Doi: 10.1007/978-3-662-03714-0_26

Heck B, Rummel R (1990) Strategies for solving the vertical datum problem using terrestrial and satellite geodetic data. In: Sea Surface Topography and the Geoid, IAG Symposia, vol 104, pp 116-128. Doi:10.1007/978-1-4684-7098-7_14

Hernández JN, Blitzkow D, Luz R, Sánchez L, Sandoval P, Drewes H (2002) Connection of the vertical control networks of Venezuela, Brazil and Colombia. In: Vertical Reference Systems, IAG Symposia, vol 124, pp 324-327. Doi: 10.1007/978-3-662-04683-8_60

Ihde J, Sánchez L (2005) A unified global height reference system as a basis for IGGOS. J Geod 40(4-5):400-413. Doi: 10.1016/j.jog.2005.06.015

Kotsakis C, Katsambalos K, Ampatzidis D (2012) Estimation of the zero-height geopotential level $W_{o}^{\mathrm{LVD}}$ in a local vertical datum from inversion of co-located GPS, leveling and geoid heights: a case study in the Hellenic islands. J Geod 86(6):423-439. Doi: 10.1007/s00190011-0530-7

Montecino HD, de Freitas SRC (2014) Strategies for connecting Imbituba and Santana Brazilian datums based on satellite gravimetry and residual terrain model. In: Earth on the Edge: Sci Sustain Planet, IAG Symposia, vol 139, pp 543-549. Doi: 10.1007/978-3642-37222-3_72

Pavlis NK, Holmes SA, Kenyon SC, Factor JK (2012) The development and evaluation of the earth gravitational model 2008 (EGM2008). J Geophys Res Solid Earth 117:B04406. Doi: 10.1029/2011JB008916

Pavlis NK, Holmes SA, Kenyon SC, Factor JK (2013) Correction to the development and evaluation of the earth gravitational model 2008 (EGM2008). J Geophys Res 118(5):2633-2633. Doi: 10.1002/jgrb.50167

Poutanen M, Vermeer M, Mäkinen J (1996) The permanent tide in GPS positioning. J Geod 70(8):499-504. Doi: 10.1007/s001900050038

Rülke A, Liebsch G, Sacher M, Schäfer U, Schirme U, Ihde J (2012) Unification of European height system realizations. J Geod Sci 2(4):343-354. Doi: 10.2478/v10156-011-0048-1

Sánchez L (2007) Definition and realization of the SIRGAS vertical reference system within a globally unified height system. IAG Symposia 130:638-645. Doi: 10.1007/978-3-540-49350-1_9

Yi W, Rummel R (2014) A comparison of GOCE gravitational models with EGM2008. J Geod 73:14-22. Doi: 10.1016/j.jog.2013.10.004 